\title{
FOREWORD
}

\section{Special Issue on Crop Insurance and Risk Management}

\section{Calum G. Turvey}

The role of crop insurance and new risk management tools for agriculture is evolving at an almost dizzying pace. One needs only to examine recent postings on the Risk Management Agency's website to see how expansive this is. Moreover, throughout the world we are witness to a host of new programs available in both developed and developing countries that are largely based on the U.S. experience. It is necessary that academics first recognize the scope of issues facing production and market risks in agriculture and then respond with new and creative ways to address the problems. To these needs, the Crop Insurance and Risk Management Workshop-the provenance of the papers in this volume-was designed to bring academics with research and extension responsibilities together with industry to explore this everchanging landscape and discuss research and outreach of mutual interest.

The scope of research in this volume is illustrative of the research and outreach efforts. Jerry Skees in a keynote address showed, perhaps more than any, the extent to which our research expands beyond the border by examining index insurance for pastoralists in Outer Mongolia and elsewhere. Robert O'Connor, in an invited paper, then provides a view of risk management from the perspective of an NSF grant administrator. Wesley Musser, also in an invited paper, illustrates crop insurance delivery from an extension point of view.

Terry Hanson and his colleagues then provide a very imaginative approach to managing disease and mortality risk in the catfish industry, while Saleem Shaik and colleagues look at insurance possibilities for trout agriculture. Both of these

Calum Turvey is the W.I. Myers Professor of Agricultural Finance in the Department of Applied Economics and Management at Cornell University in Ithaca, New York. papers provide novel approaches to deal with emerging risks in an ever-more diversified agricultural economy, one which now blends with fisheries to deal with aquaculture. Likewise Nicholas Paulson and his colleagues have recognized the growing industrial base for ethanol, especially in the Midwest, and have developed an innovative approach to managing risks in the ethanol industry. Working with the Iowa Corn Growers Association, they developed a technique to hedge gross margin risk using futures contracts. In a different arena, but nonetheless a very new area of study, Calum Turvey and Michael Norton present their online computer program that can be used to evaluate a variety of insurance policies for specific-event heat and precipitation risks at any one of the thousands of weather stations dotting the United States. Their program also provides an approach to computing joint events and basis risk.

The workshop also included papers more traditionally associated with crop insurance. The ageold problem of measuring crop yield distributions for insurance purposes was tackled by Yue Lu and her coauthors, who introduce to us the structure and flexibility of the Johnson family of probability distributions. From Canada, Juan Cabas, Akssell Leiva, and Alfons Weersink model the crop insurance exit and entry decisions of Ontario farmers in response to changing weather events or changes in crop yield variability. Roderick Rejesus and his colleagues provide a paper dealing with the information stock and flows that influence crop insurance decisions, while Paul Mitchell and Thomas Knight provide a policy overview of the Supplemental Deductible Coverage as recommended in the 2007 Farm Bill to assist farmers in high-risk areas where premiums and deductibles exceed profit margins. 
The workshop at which these papers were presented was held on June $12-13$ at the 2007 NAREA meetings at Rehoboth Beach Delaware. We are grateful to the Farm Foundation and the Risk Management Agency for financial support of the workshop as well as the publication of this issue. Thanks also go to Wes Musser for helping to organize the session, in addition to delivering one of the keynote addresses. On behalf of the authors and workshop participants, I would like also to extend thanks to the journal editors for guiding the efficient and timely peer review process that brought about this issue. 